\title{
CrystEngComm
}

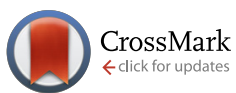

Cite this: CrystEngComm, 2015, 17, 1483

Received 14th October 2014,

Accepted 2nd January 2015

DOI: $10.1039 / \mathrm{c} 4 \mathrm{ce} 02070 \mathrm{~g}$

www.rsc.org/crystengcomm

\section{On the concomitant crystallization of amino acid crystals upon dissolution of some amino acid salt crystals $\uparrow$}

\author{
L. J. M. Kempkes and W. J. P. van Enckevort*
}

During our in situ microscopy experiments we found that dissolution of glutamic acid, aspartic acid and leucine chloride single crystals leads to the spontaneous formation of numerous glutamic acid, aspartic acid and leucine crystals respectively. This phenomenon was not encountered during dissolution of monosodium glutamate single crystals. The observations are interpreted on the basis of calculated phase diagrams of the amino acid/HCl $(/ \mathrm{NaOH})$ systems. It was shown that upon dissolving the halide salts one enters the liquid-solid amino acid domain in the phase diagram, leading to the crystallization of the amino acids. The conclusions were confirmed by triple point composition measurements using several analytical methods.

\section{Introduction}

Chirality is an important characteristic of nearly all amino acids. Because of this property, amino acid (salt) single crystals show interesting non-linear optical properties, which, for instance, can be used for frequency doubling of laser light. ${ }^{1-3}$ In addition, left handed amino acids are the basic building blocks of protein molecules and therefore are highly relevant for understanding life and pharmaceutical applications. Enantiopure amino acids can, for instance, be extracted from nature or obtained by asymmetric synthesis. Another possibility is by separation of enantiomers from a racemic mixture of conglomerate crystals as was first demonstrated by Louis Pasteur in $1848 .{ }^{4}$ In this he manually selected left and right hand sodium tartrate crystals by looking at the mirror image shapes of the two crystal groups. Later, the method was improved by adding a seed crystal of desired handedness to a stirred, supersaturated solution, yielding maximally $50 \%{ }^{5}$ or in some cases $100 \%$ solid material of single chirality. ${ }^{6}$ More recently, Viedma introduced a method based on grinding conglomerate crystals in contact with a saturated, racemizing solution yielding sodium chlorate crystals of $100 \%$ pure chirality. ${ }^{7}$ This approach, now known as "Viedma ripening", was also shown to be applicable for deracemizing amino acids, its salts and its derivates. ${ }^{8-10}$ Crystallization is also important in the production of sodium glutamate

Radboud University, Institute for Molecules and Materials, Heyendaalseweg 135, 6525 AJ Nijmegen, The Netherlands. E-mail: w.vanenckevort@science.ru.nl $\dagger$ Electronic supplementary information (ESI) available. See DOI: 10.1039/ c4ce02070g monohydrate on a larger industrial scale, for its use as the umami taste component in Asiatic food. Obtaining this compound involves several crystallization steps. After bacterial fermentation of molasses or other sugar containing materials, this compound is purified by crystallization as - low solubility glutamic acid. This deposit is dissolved again by adding caustic soda to the liquid and then recrystallized as monosodium glutamate by solvent evaporation. ${ }^{11,12}$ All these examples show that understanding the crystallization of amino acids and its salts is quite relevant, both in laboratory and industry.

In an attempt to in situ study the surface morphology of glutamic acid hydrochloride crystals by using optical microscopy and atomic force microscopy, we encountered many problems. During our investigation of the crystals in (super) saturated solution, the surfaces of the crystals became covered by numerous microcrystals, completely deteriorating the original surface patterns. Further experiments showed that the same crystallites also formed during dissolution of the glutamic acid hydrochloride crystals in water. The crystallites were identified as glutamic acid. To solve this "riddle" of concomitant crystallization of amino acid crystals upon growth or dissolution of the corresponding amino acid salt crystals, experiments and phase diagram calculations were performed for four different amino acid cases. The calculations were verified by triple point composition measurements.

\section{Experimental}

\subsection{Materials and crystal growth}

L-Glutamic acid, monosodium L-glutamate monohydrate, L-aspartic acid and L-leucine (99\% purity) were purchased 
from Sigma Aldrich. Crystals of these compounds were obtained by slow cooling and/or evaporation of supersaturated aqueous solutions. Glutamic acid hydrochloride, aspartic acid hydrochloride and di-leucine hydrochloride were synthesized. The amino acid hydrochlorides were obtained from a 1:1 molar ratio of amino acid and 37\% concentrated hydrochloride (99\% purity). The hydrochloride is added to a saturated solution of amino acid in water, in contact with an appropriate amount of solid amino acid. This mixture is stirred and heated till a temperature of $60-80{ }^{\circ} \mathrm{C}$. A bit of excess of hydrochloride was used to ensure that all amino acid reacted with the hydrochloride. When the amino acid is dissolved completely, stirring is stopped and the solution is cooled down to room temperature, partially evaporated and halide salt crystals are formed. After separation of the crystals, these are dissolved in water acidized with a slight amount of $\mathrm{HCl}$ and recrystallized by slow, controlled evaporation at room or slightly higher temperature. In this way well formed amino acid halide crystals of a few $\mathrm{mm}$ in size were obtained.

Leucine hydrochloride can crystallize in two forms, namely as di-leucine hydrochloride ${ }^{13}$ and leucine hydrochloride monohydrate. ${ }^{14}$ Single crystal X-ray analysis of one of the crystals obtained by the above mentioned method, showed that in our case it concerns the di-leucine hydrochloride species. This agrees with the elongated prismatic shape of the crystals, ${ }^{13}$ rather than being plates as expected for leucine hydrochloride monohydrate. ${ }^{14}$

\subsection{Composition analysis}

To determine solubility and triple point compositions for the different amino acid hydrochloride (sodium hydroxide) systems several analytical methods were applied.

High-Performance Liquid Chromatography (HPLC) measurements were performed on an Agilent 1260 Infinity apparatus to determine amino acid concentrations. For glutamic acid, the injection volume is $10 \mu \mathrm{L}$, the used column Chirobiotic $\mathrm{T}(250 \times 4.6 \mathrm{~mm}$ ID $), 5 \mathrm{~m}$, Astec; the eluent was methanol/water/formic acid 80/20/0.2 v/v/v, flow

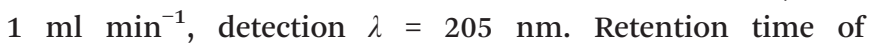
L-glutamic acid is $5.7 \mathrm{~min}$. For aspartic acid, the injection volume is $10 \mu \mathrm{L}$, the column used Chirobiotic $\mathrm{T}(250 \times 4.6 \mathrm{~mm}$ ID), $5 \mathrm{~m}$, Astec; the eluent is $65: 30$ ethanol/water $+0.02 \%$

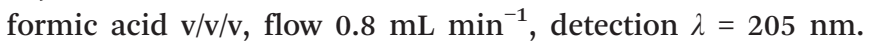
Retention time of $\mathrm{L}$-aspartic acid is $6.1 \mathrm{~min}$.

Chloride concentrations in the solution were measured by titration following Mohr's method, using potassium chromate as indicator. ${ }^{15}$ Sodium concentrations were determined by Inductively Coupled Plasma Mass Spectroscopy (ICP-MS). In this the samples were diluted 4000 times in water, as the detection range of ICP-MS is $10-50 \mathrm{mg} \mathrm{L}^{-1}$. The $\mathrm{pH}$ of the solutions was measured with a standard $\mathrm{pH}$ meter (Inolab WTW-series, pH 720). The total weight of amino acid plus amino acid salt was determined by weighting the solid after solvent evaporation and careful drying in a desiccator.

\subsection{Crystal characterization and identification}

The crystal growth processes, crystal morphologies were observed both in situ and ex situ by optical microscopes fitted with a CCD camera connected to a computer. The microscopes used were a polarization microscope (Leica DM-RXHC-Pol) and a bright field (Zeiss Axioplan 2) microscope, both in transmission mode. For the in situ observations the crystals were grown or dissolved in smaller (5 $\mathrm{cm}$ diameter) petri dishes. Scanning electron microscopy was used for ex situ observations of leucine and di-leucine hydrochloride crystals at higher magnification. In this the surface of the crystals was sputter coated by a thin layer of gold-palladium prior to examination.

Identification of the crystals was based on crystal morphology, which is significantly different for the different compounds. The various crystal identities were verified by single-crystal X-ray diffraction and powder X-ray diffraction. Single crystal X-ray diffraction data was collected on a Bruker Nonius Kappa CCD diffractometer using MoK $\alpha$ radiation. Data reduction and structure determination were performed using the program SHELXL-97. ${ }^{16}$ Powder diffraction patterns were measured on a Bruker D2 Phaser and a Bruker D8 diffractometer using $\mathrm{CuK} \alpha$ radiation.

\section{Observations}

\subsection{L-Glutamic acid hydrochloride and monosodium L-glutamate monohydrate}

Crystallization from a slightly supersaturated glutamic acid hydrochloride solution in water by slow solvent evaporation always results in the concomitant crystallization of $\beta$-glutamic acid polymorph and glutamic acid hydrochloride salt crystals, as shown in Fig. 1. This simultaneous crystallization occurs if the solution is prepared by dissolving glutamic acid hydrochloride crystals in water as well as by preparing the solution by adding equimolar amounts of glutamic acid and $\mathrm{HCl}$ in water. Both crystal types persist when the solution comes to equilibrium after a longer

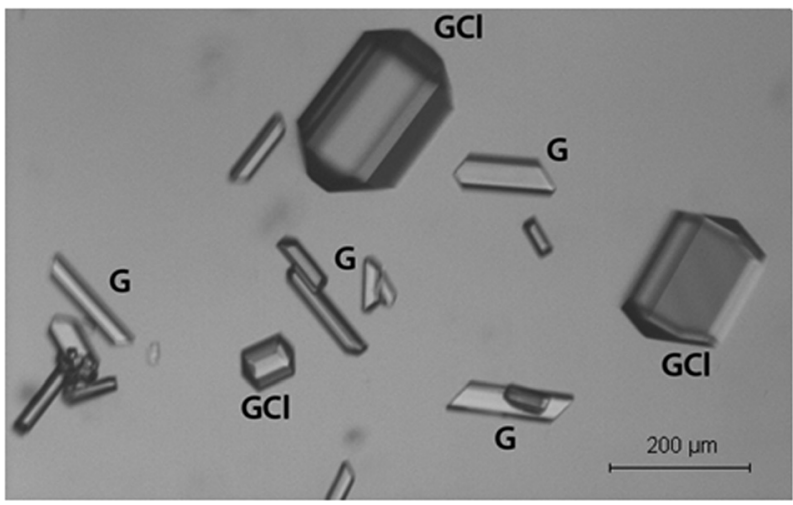

Fig. 1 In situ micrograph of crystals of glutamic acid hydrochloride (GCl) and $\beta$-glutamic acid (G) formed after crystallization from a 1:1 solution of glutamic acid and $\mathrm{HCl}$ in water. 
period. The identity of the crystals was verified by single crystal and powder X-ray diffraction.

More interesting is the observation that upon dissolving glutamic acid hydrochloride single crystals in pure water rapidly leads to the formation of numerous smaller needlelike crystals as shown in Fig. 2. These crystals were identified as $\beta$-glutamic acid. So, in an undersaturated solution of glutamic acid hydrochloride, crystals of $\beta$-glutamic acid are easily formed. This formation of secondary microcrystals during growth and dissolution of glutamic acid hydrochloride crystals accounts for the problems encountered during our AFM studies.

In contrast to the hydrochloride salt of glutamic acid, dissolving monosodium glutamate monohydrate crystals in water did not lead to the formation of glutamic acid or other crystals (Fig. 3).

\subsection{L-Aspartic acid hydrochloride and di-L-leucine acid hydrochloride}

The dissolution experiments as described above were repeated for both $\mathrm{L}$-aspartic acid hydrochloride and di-L-leucine hydrochloride crystals. Partial dissolution of L-aspartic acid hydrochloride crystals in water leads to the development of numerous aspartic acid microcrystals. This results in hedgehog-like features as shown in Fig. 4.

Similar to the other two amino acid halides, solving di-L-leucine hydrochloride crystals in water also results in the development of numerous microcrystals. In situ optical microscopy and ex situ scanning electron microscopy showed thin, planar crystallites growing more or less perpendicularly on top of the dissolving di-L-leucine hydrochloride single crystals (Fig. 5). Based on their shape the microcrystallite plates were identified as L-leucine, which was confirmed by $\mathrm{X}$-ray powder diffraction.

Evaporation of $\mathrm{HCl}$ from the solution leading to the formation of amino acid crystals upon dissolution of their

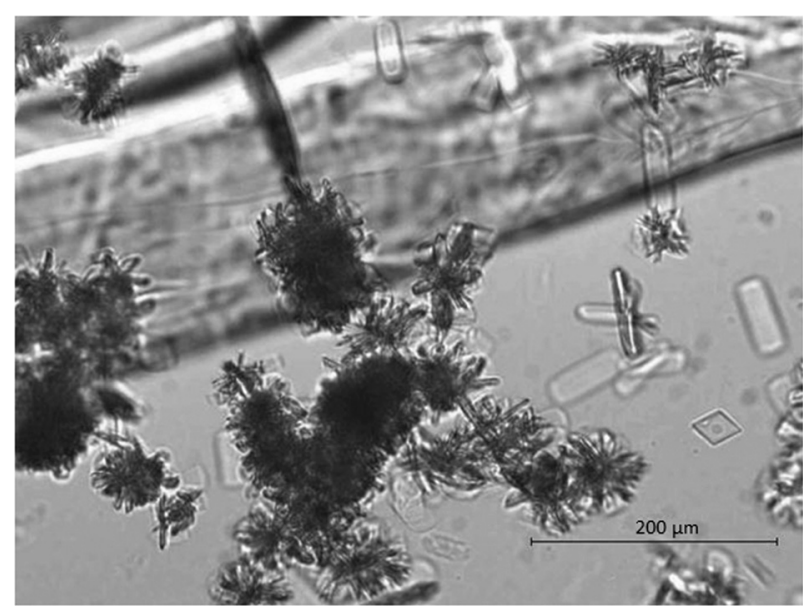

Fig. 2 In situ optical micrograph showing the formation of numerous $\beta$-glutamic acid micro crystals during dissolution of a larger glutamic acid hydrochloride single crystal (upper half of the image) in water.

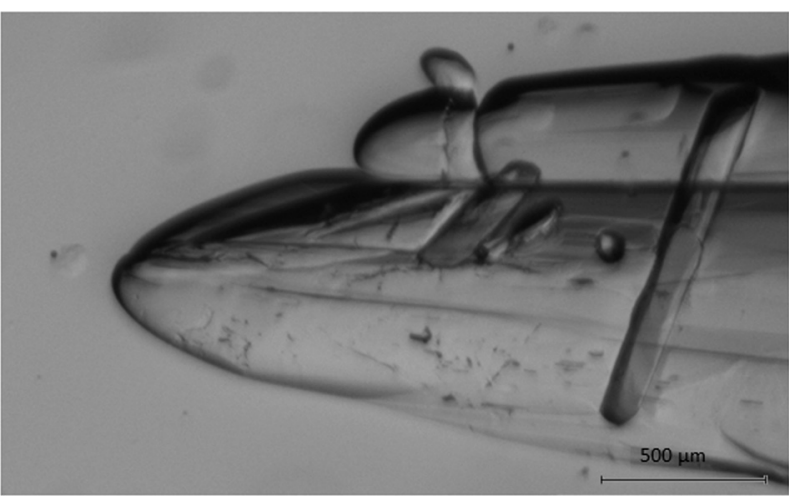

Fig. 3 In situ micrograph showing the dissolution of a monosodium glutamate monohydrate crystal in water. No micro crystallites are produced in this case.

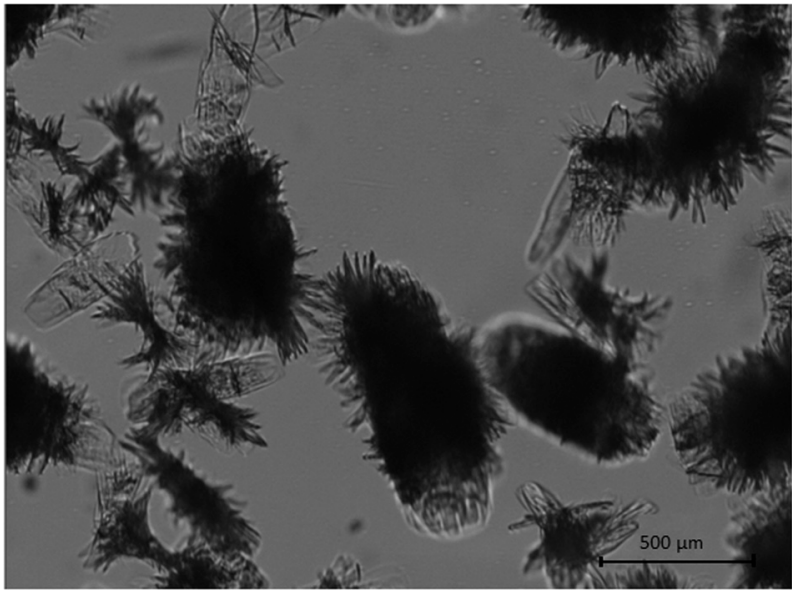

Fig. 4 In situ optical micrograph showing the creation of L-aspartic acid microcrystals upon dissolution of L-aspartic acid hydrochloride crystals in water. The bodies of the hedgehog-like features are dissolving L-aspartic acid hydrochloride crystals, whereas the spines represent thin L-aspartic acid crystals.

hydrochloride salts does not explain our observations. As shown in paragraph 4 of the manuscript the concentrations of $\mathrm{H}^{+}$and $\mathrm{Cl}^{-}$are far below the critical value of 9 molal $\mathrm{HCl}$ in water. Below this concentration value, the vapor pressure ratio of $\mathrm{HCl}$ and $\mathrm{H}_{2} \mathrm{O}$ is less than the concentration ratio in the solution. ${ }^{17,18}$ So, for this concentration regime relatively more $\mathrm{H}_{2} \mathrm{O}$ evaporates and the solution becomes more acidic, hindering the formation of the neutral amino acid species. This is contrary to our observations. Moreover, the amino acid crystals are formed rapidly upon dissolution of the salt crystals; this happens before significant solute evaporation takes place.

\section{Phase diagrams}

\subsection{Phase diagram calculations}

To obtain insight in the concomitant crystallization of amino acids during the growth and dissolution of amino acid halides, phase diagrams of the ternary system Amino acid (A) - 

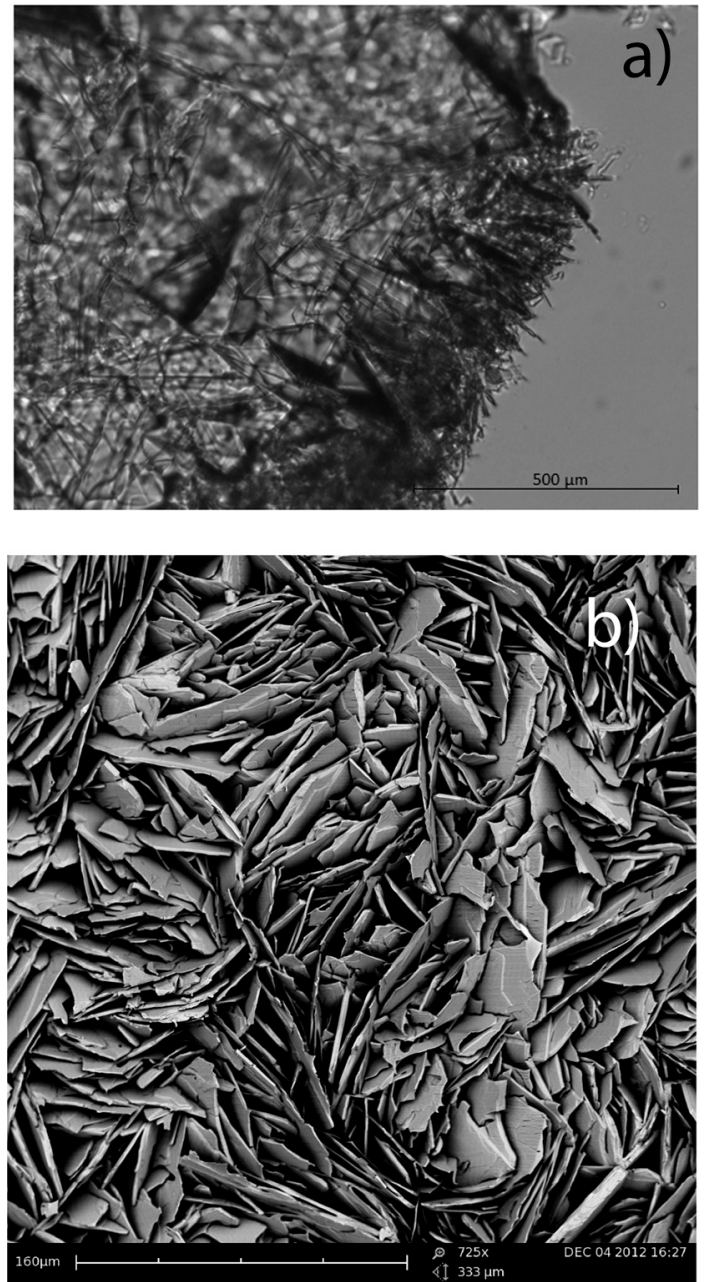

Fig. 5 Solving di-L-leucine hydrochloride crystals in water results in the growth of numerous L-leucine microcrystals. (a) In situ optical micrograph; (b) Scanning Electron Microscopy image showing the platelet shape of the L-leucine microcrystals grown on top of a di-L-leucine hydrochloride single crystal.

amino acid hydrochloride $(\mathrm{ACl})$ in water are calculated for L-Glutamic acid (Glu), L-Aspartic acid (Asp) and (partially for) L-Leucine (Leu). In addition, the system glutamic acid-monosodium glutamate is calculated, which is detailed in ESI- $1 . \dagger$ In the calculations we use molarities instead of activities, as the latter are not known.

B. Harjo et al. ${ }^{19}$ showed that the use of phase diagrams is very helpful in the design of amino acid (salt) crystallization processes on an industrial scale.
4.1.1 Equilibria and triple point values. Glutamic acid and aspartic acid can occur in four forms in aqueous solution, depending on the $\mathrm{pH}$ : The neutral species $\mathrm{A}$, the positively charged $\mathrm{A}^{+}$and two negatively charged species $\mathrm{A}^{-}$and $\mathrm{A}^{2-}$. For leucine the $\mathrm{A}^{2-}$ form does not occur. In these systems the following equilibria exist with the associated equilibrium constants and solubilities $\mathrm{A}_{\text {solid }}$ and $\mathrm{ACl}_{\text {solid }}$, which are given in Table 1 for the different amino acids:

$$
\begin{gathered}
{\left[\mathrm{A}^{+}\right]+\left[\mathrm{H}_{2} \mathrm{O}\right] \leftrightarrow[\mathrm{A}]+\left[\mathrm{H}_{3} \mathrm{O}^{+}\right] ; \frac{[\mathrm{A}]\left[\mathrm{H}_{3} \mathrm{O}^{+}\right]}{\left[\mathrm{A}^{+}\right]}=K_{a 1}} \\
{[\mathrm{~A}]+\left[\mathrm{H}_{2} \mathrm{O}\right] \leftrightarrow\left[\mathrm{A}^{-}\right]+\left[\mathrm{H}_{3} \mathrm{O}^{+}\right] ; \quad \frac{\left[\mathrm{A}^{-}\right]\left[\mathrm{H}_{3} \mathrm{O}^{+}\right]}{[\mathrm{A}]}=K_{a 2}} \\
{\left[\mathrm{~A}^{-}\right]+\left[\mathrm{H}_{2} \mathrm{O}\right] \leftrightarrow\left[\mathrm{A}^{2-}\right]+\left[\mathrm{H}_{3} \mathrm{O}^{+}\right] ; \frac{\left[\mathrm{A}^{2-}\right]\left[\mathrm{H}_{3} \mathrm{O}^{+}\right]}{\left[\mathrm{A}^{-}\right]}=K_{a 3}} \\
2\left[\mathrm{H}_{2} \mathrm{O}\right] \leftrightarrow\left[\mathrm{H}_{3} \mathrm{O}^{+}\right]+\left[\mathrm{OH}^{-}\right] ; \quad\left[\mathrm{H}_{3} \mathrm{O}^{+}\right]\left[\mathrm{OH}^{-}\right]=K_{\mathrm{w}} \\
{[\mathrm{A}] \leftrightarrow \mathrm{A}_{\text {solid }} \quad\left[\mathrm{A}_{\mathrm{slb}}\right]=K_{\mathrm{A}}} \\
{\left[\mathrm{A}^{+}\right]+\left[\mathrm{Cl}^{-}\right] \leftrightarrow \mathrm{ACl}_{\text {solid }} \quad\left[\mathrm{A}^{+}\right]\left[\mathrm{Cl}^{-}\right]=K_{\mathrm{ACl}}}
\end{gathered}
$$

The first step in the computation of the phase diagram is calculating the solubility of the neutral species, $\left[\mathrm{A}_{\mathrm{slb}}\right]$ in contact with the solid amino acid in water. If an amino acid is dissolved in water, a mixture of $A, A^{+}$and $A^{-}$is obtained. So, the total solubility of the amino acid, $\left[\mathrm{A}_{\text {tot }}\right]$, comprises

$$
\left[\mathrm{A}_{\mathrm{tot}}\right]=\left[\mathrm{A}^{+}\right]+\left[\mathrm{A}_{\mathrm{slb}}\right]+\left[\mathrm{A}^{-}\right]
$$

The solubility $\left[\mathrm{A}_{\mathrm{slb}}\right]$ can be calculated using the experimental value of $\left[A_{t o t}\right]$ and solving eqn (1), (2), (4), (7) (neglecting $\left[\mathrm{A}^{2-}\right]$ ) plus the neutrality condition

$$
\left[\mathrm{A}^{+}\right]+\left[\mathrm{H}_{3} \mathrm{O}^{+}\right]=\left[\mathrm{A}^{-}\right]+\left[\mathrm{OH}^{-}\right]
$$

Experimental values of $\left[\mathrm{A}_{\text {tot }}\right]$ from literature and calculated values of $\left[\mathrm{A}_{\mathrm{slb}}\right]$ for glutamic acid, aspartic acid and leucine are given in Tables 1 and 2 respectively. The second step is deriving the solubility constant $K_{\mathrm{ACl}}$, using the experimental concentration, $\left[\mathrm{ACl}_{\mathrm{tot}}\right]$, of a saturated $\mathrm{ACl}$ solution (Table 1$) . *$

Table 1 Input parameters used for the calculation of the amino acid/HCl phase diagrams

\begin{tabular}{llll}
\hline Input parameters & Values Glu/HCl & Values Asp/HCl & Values Leu/HCl \\
\hline$K_{a 1}$ (ref. 20) & $10^{-2.19} \mathrm{M}$ & $10^{-1.88} \mathrm{M}$ & $10^{-2.36} \mathrm{M}$ \\
$K_{a 2}$ (ref. 20) & $10^{-4.25} \mathrm{M}$ & $10^{-3.65} \mathrm{M}$ & $10^{-9.60} \mathrm{M}$ \\
$K_{a 3}$ (ref. 20) & $10^{-9.67} \mathrm{M}$ & $10^{-9.60} \mathrm{M}$ & - \\
Solubility A; $\left[\mathrm{A}_{\text {tot, }, 0]}\right.$ & $0.0558 \mathrm{M}^{b}$ (ref. 21 and 22) & $0.0316 \mathrm{M}$ (ref. 23) & $0.163 \mathrm{M}$ (ref. 24) \\
Estimated solubility ACl: $\left[\mathrm{ACl}_{\text {tot }}\right]$ & $\approx 1.88 \mathrm{M}$ & $\approx 1.33 \mathrm{M}$ & -
\end{tabular}

${ }^{a}$ Concentrations and equilibria are expressed in terms of molarities, M. ${ }^{b}$ Average values from ref. 21 and $22 .^{c} K_{\mathrm{w}}$ at $20{ }^{\circ} \mathrm{C}=14.17$. 
Table 2 Calculated parameters/concentrations for the three amino acid/ $\mathrm{HCl}$ systems ${ }^{a}$

\begin{tabular}{llll}
\hline $\begin{array}{l}\text { Calculated parameters/ } \\
\text { concentrations }\end{array}$ & $\begin{array}{l}\text { Values } \\
\text { Glu/HCl }\end{array}$ & $\begin{array}{l}\text { Values } \\
\text { Asp/HCl }\end{array}$ & $\begin{array}{l}\text { Values } \\
\text { Leu/HCl }\end{array}$ \\
\hline$\left[\mathrm{A}_{\text {slb }}\right]=K_{\mathrm{A}}$ & $0.0470 \mathrm{M}$ & $0.032 \mathrm{M}$ & $0.0239 \mathrm{M}$ \\
$K_{\mathrm{ACl}}=\left[\mathrm{A}^{+}\right]\left[\mathrm{Cl}^{-}\right]$ & $3.333 \mathrm{M}^{2}$ & $1.60 \mathrm{M}^{2}$ & - \\
{$\left[\mathrm{A}_{\text {tot }}\right]_{\text {trip }}$} & $1.759 \mathrm{M}$ & $1.095 \mathrm{M}$ & - \\
{$\left[\mathrm{Cl}^{-}\right]_{\text {trip }}$} & $1.947 \mathrm{M}$ & $1.507 \mathrm{M}$ & - \\
{$\left[\mathrm{H}^{+}\right]_{\text {trip }}$} & $0.235 \mathrm{M}$ & $0.44 \mathrm{M}$ & -
\end{tabular}

${ }^{a}$ Concentrations and equilibria are expressed in terms of molarities, $\mathbf{M}$.

This can be computed by (numerically) solving eqn (1), (2), (4) and (6) including the neutrality condition

$$
\left[\mathrm{A}^{+}\right]+\left[\mathrm{H}_{3} \mathrm{O}^{+}\right]=\left[\mathrm{A}^{-}\right]+\left[\mathrm{OH}^{-}\right]+\left[\mathrm{Cl}^{-}\right]
$$

and considering the two facts that

$$
\left[\mathrm{ACl}_{\text {tot }}\right]=\left[\mathrm{A}^{-}\right]+[\mathrm{A}]+\left[\mathrm{A}^{+}\right]
$$

and the chlorine is completely ionized

$$
\left[\mathrm{Cl}^{-}\right]=\left[\mathrm{ACl}_{\text {tot }}\right]
$$

This gives $\left[\mathrm{A}^{+}\right]$and $\left[\mathrm{Cl}^{-}\right]$and thus the equilibrium constants $K_{\mathrm{ACl}}$ for glutamic acid and aspartic acid chloride as given in Table 2. It is assumed that the concentration of $\mathrm{A}^{2-}$ can be neglected.

At the triple point of the amino acid-HCl phase diagram, solid amino acid and solid amino acid hydrochloride are in equilibrium with the aqueous solution. Using the different equilibrium constants, $K$, the six concentrations $[\mathrm{A}],\left[\mathrm{A}^{+}\right],\left[\mathrm{A}^{-}\right]$, $\left[\mathrm{H}_{3} \mathrm{O}^{+}\right],\left[\mathrm{OH}^{-}\right]$and $\left[\mathrm{Cl}^{-}\right]$at this point can be calculated by numerically solving the set of six eqn (1), (2), (4), (5), (6) and (9). From these values the total amino acid and chlorine concentrations in the solution at the triple point readily follow from eqn (10) and the fact that $\left[\mathrm{Cl}^{-}{ }_{\text {tot }}\right]=\left[\mathrm{Cl}^{-}\right]$. Results for the glutamic acid $/ \mathrm{HCl}$ and aspartic acid/ $\mathrm{HCl}$ systems are given in Table 2.

4.1.2 Constructing the phase diagrams. Fig. $6 a-d$ show the calculated phase diagrams of the systems glutamic acid/ $\mathrm{HCl}$, aspartic acid/HCl, glutamic acid/NaOH (See ESI-1 $\dagger$ ) and (partially) leucine/HCl. The $L-L+A_{\mathrm{s}}$ boundary line is calculated by solving the set of eqn (1), (2), (4), (5), (7), (9) for [ $\left.A_{t o t}\right]$ as a function of $\left[\mathrm{Cl}^{-}\right]$.

If amino acid is added to a solution corresponding with the triple point, the composition of the solution does not change and only solid amino acid is formed. This implies a vertical $\mathrm{L}+\mathrm{A}_{\mathrm{s}}-\mathrm{L}+\mathrm{A}_{\mathrm{s}}+\mathrm{ACl}_{\mathrm{s}}$ boundary line starting from the triple point. Similarly, if amino acid hydrochloride is added to a triple point solution, only solid $\mathrm{ACl}_{\mathrm{s}}$ is formed.

\$ As a first approximation we assume that no solid amino acid crystals are formed in using the literature values. Likely a small amount of $\mathrm{HCl}$ is added to the saturated solutions to avoid co-precipitation of solid amino acid crystals. So, the actual $\left[\mathrm{ACl}_{\text {tot }}\right]$ might be slightly different.
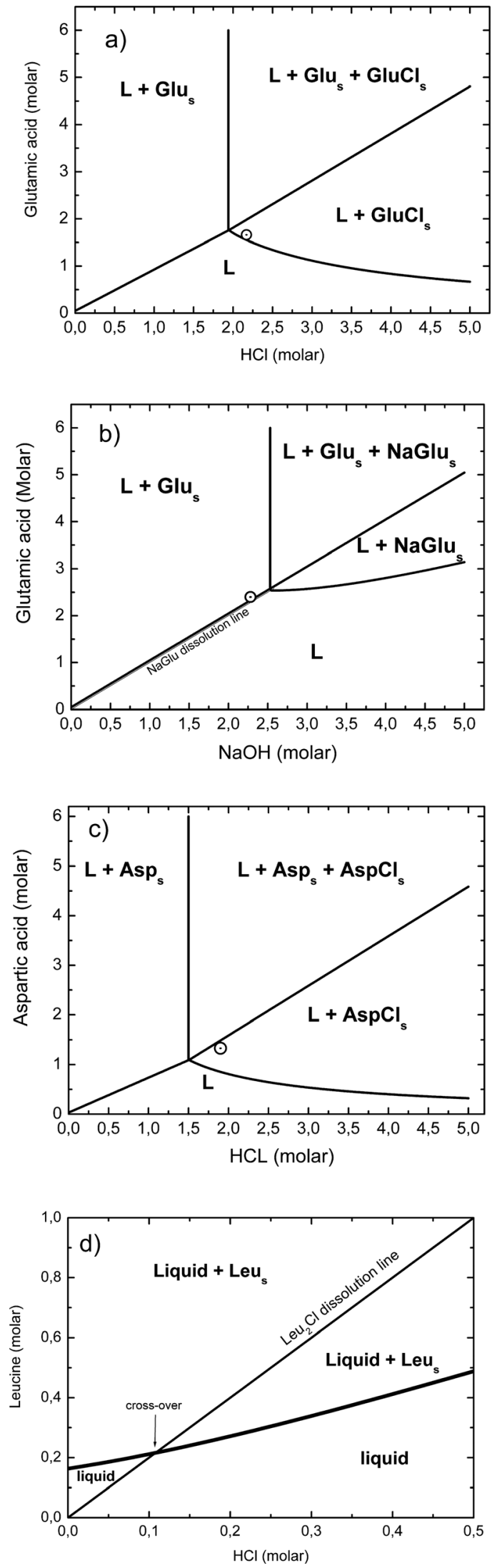

Fig. 6 Calculated phase diagrams of the systems glutamic acid/ $\mathrm{HCl}$, glutamic acid/ $\mathrm{NaOH}$, aspartic acid/ $\mathrm{HCl}$ and (partially) leucine $/ \mathrm{HCl}$. In the first three of the diagrams the experimentally determined triple point is indicated by a small circle. 
Therefore, in the phase diagram the $\mathrm{L}+\mathrm{A}_{\mathrm{s}}+\mathrm{ACl}_{\mathrm{s}}-\mathrm{L}+\mathrm{ACl}_{\mathrm{s}}$ boundary is a straight line with slope one, starting from the triple point.

The $\mathrm{L}-\mathrm{L}+\mathrm{ACl}_{\mathrm{s}}$ border line is calculated by solving the set of eqn (1), (2), (4), (6), (7) and (9) for $\left[A_{t o t}\right]$ as a function of $\left[\mathrm{Cl}^{-}\right]$.

As a consequence of its complete ionization $\left[\mathrm{Cl}^{-}\right]$is identical to the total amount of $\mathrm{HCl}$ added to the system.

\subsection{Implications}

If one dissolves pure amino acid hydrochloride crystals in water, then one follows the trajectory $\left[\mathrm{A}_{\mathrm{tot}}\right]=\left[\mathrm{Cl}^{-}\right]\left(=\mathrm{HCl}_{\mathrm{added}}\right)$ in the phase diagrams. Closer examination of the glutamic acid/HCl and aspartic acid/HCl diagrams shows that this line crosses the $\mathrm{L}-\mathrm{L}+\mathrm{A}_{\mathrm{S}}$ line in both diagrams and enters the $\mathrm{L}+\mathrm{A}_{\mathrm{s}}$ domain (shown for GluCl in Fig. 7). This leads to the concomitant crystallization of amino acid upon dissolution of the two amino acid hydrochloride species, which agrees with our observations. The calculated cross-over point is at $0.41 \mathrm{~mol}$ per liter dissolved GluCl and $0.11 \mathrm{~mol}$ per liter AspCl.

Upon dissolution of dileucine hydrochloride crystals, the dissolution line follows the trajectory $\left[\mathrm{Leu}_{\text {tot }}\right]=2\left[\mathrm{Cl}^{-}\right]$and readily enters the $\mathrm{L}+\mathrm{Leu}_{\mathrm{s}}$ domain, resulting in concomitant crystallization of leucine crystals as observed. As shown in Fig. 6d the cross-over point of the $\mathrm{Leu}_{2} \mathrm{Cl}$ dissolution line with the $\mathrm{L}+$ $\mathrm{Leu}_{2}$ boundary is at $\mathbf{0 . 1 1} \mathrm{mol}$ per liter dissolved $\mathrm{Leu}_{2} \mathrm{Cl}$.

For NaGlu, the NaGlu dissolution line, i.e. the trajectory $\left[\mathrm{A}_{\text {tot }}\right]=\left[\mathrm{Na}^{+}\right]\left(=\mathrm{NaOH}_{\text {added }}\right)$, is always below the $\mathrm{L}-\mathrm{L}+\mathrm{A}_{\mathrm{s}}$ boundary line in the phase diagram (ESI-1†). This implies that these lines do not cross and no solid glutamic acid is formed upon dissolution of sodium glutamine monohydrate in water. This agrees with our observations.

\subsection{A simple criterion for the concomitant crystallization during dissolution}

If the $\mathrm{ACl}$ dissolution trajectory $\left[\mathrm{A}_{\mathrm{tot}}\right]=\left[\mathrm{Cl}^{-}\right]\left(=\mathrm{HCl}_{\mathrm{added}}\right)$ crosses the $\mathrm{L}-\mathrm{L}+\mathrm{A}_{\mathrm{S}}$ boundary line, then concomitant crystallization of amino acid will occur upon dissolving amino acid hydrochloride crystals in water. To determine the intersection point of both lines, we approximate the $\mathrm{L}-\mathrm{L}+\mathrm{A}_{\mathrm{s}}$ boundary as a straight line starting from the total solubility of the amino acid $\left[\mathrm{A}_{\text {tot, } 0}\right]$ at $\mathrm{HCl}_{\text {added }}=0$ to the triple point. This line ends at the triple point, where (neglecting $\mathrm{A}^{-}$) $\left[\mathrm{A}_{\text {tot,trip }}\right]=\left[\mathrm{A}_{\text {slb }}\right]+\left[\mathrm{A}_{\text {trip }}^{+}\right]$and $\mathrm{HCl}_{\text {added,trip }}=\left[\mathrm{A}_{\text {trip }}^{+}\right]+\left[\mathrm{H}_{3} \mathrm{O}_{\text {trip }}^{+}\right]$. So, assuming $\left[\mathrm{A}_{\text {tot }, 0}\right] \approx\left[\mathrm{A}_{\text {slb }}\right]$ the $\mathrm{L}-\mathrm{L}+\mathrm{A}_{\mathrm{s}}$ boundary line becomes

$$
\mathrm{A}_{\text {tot }} \cong\left[\mathrm{A}_{\text {tot }, 0}\right]+\frac{\left[\mathrm{A}_{\text {trip }}^{+}\right]}{\left[\mathrm{A}_{\text {trip }}^{+}\right]+\left[\mathrm{H}_{3} \mathrm{O}_{\text {trip }}^{+}\right]} \mathrm{HCl}_{\text {added,trip }}
$$

The intersection point corresponds with the location where

$$
\mathrm{A}_{\text {tot }}=\mathrm{HCl}_{\text {added }} \text {, }
$$

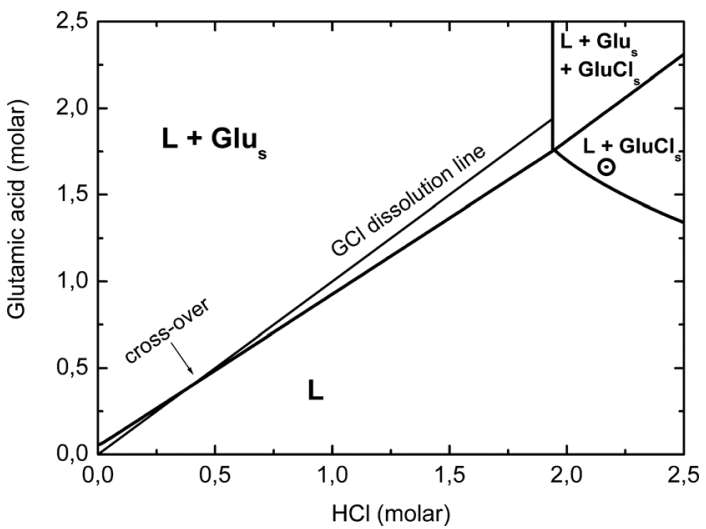

Fig. 7 Detailed view of the $\mathrm{Glu} / \mathrm{HCl}$ phase diagram showing the cross-over of the $\mathrm{GluCl}$ dissolution line and the $\mathrm{L}+\mathrm{Glu}_{\mathrm{s}}$ border line.

and eqn (12) are both satisfied. This gives the crossover point at

$$
\mathrm{A}_{\text {tot }}^{*}=\mathrm{HCl}_{\text {added }}^{*}=\frac{\left[\mathrm{A}_{\text {tot }, 0}\right]\left(\left[\mathrm{A}_{\text {trip }}^{+}\right]+\left[\mathrm{H}_{3} \mathrm{O}_{\text {trip }}^{+}\right]\right)}{\left[\mathrm{H}_{3} \mathrm{O}_{\text {trip }}^{+}\right]}
$$

If intersection occurs at a $\mathrm{HCl}^{*}$ added value less than

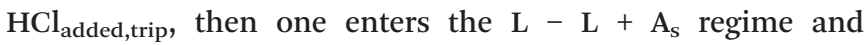
precipitation of $A_{s}$ crystals takes place. Or, if

$$
\frac{\left[\mathrm{A}_{\text {tot }, 0}\right]\left(\left[\mathrm{A}_{\text {trip }}^{+}\right]+\left[\mathrm{H}_{3} \mathrm{O}_{\text {trip }}^{+}\right]\right)}{\left[\mathrm{H}_{3} \mathrm{O}_{\text {trip }}^{+}\right]}<\mathrm{HCl}_{\text {added,trip }} \equiv\left[\mathrm{A}_{\text {trip }}^{+}\right]+\left[\mathrm{H}_{3} \mathrm{O}_{\text {trip }}^{+}\right],
$$

After rewriting, the simple criterion for the occurrence of concomitant crystallization of $\mathrm{A}_{\mathrm{s}}$ upon dissolution of $\mathrm{ACl}$ crystals can be expressed as

$$
\left[\mathrm{H}_{3} \mathrm{O}_{\text {trip }}^{+}\right] \geq\left[\mathrm{A}_{\text {tot }, 0}\right] \text {. }
$$

For the calculated value of $\left[\mathrm{H}_{3} \mathrm{O}_{\text {trip }}^{+}\right]=0.235 \mathrm{M}$ and measured $\left[\mathrm{Glu}_{\text {tot, }, 0}\right]=0.0558 \mathrm{M}$, it can readily be seen that this condition is met for glutamic acid hydrochloride. A similar conclusion can be drawn for Aspartic acid $\left(\left[\mathrm{H}_{3} \mathrm{O}_{\text {trip }}^{+}\right]=0.44 \mathrm{M}\right.$ and $\left[\right.$ Asp $\left._{\text {tot }, 0}\right]=0.0316 \mathrm{M}$.

In a similar way as derived for the amino acid hydrochloride system, a similar criterion

$$
\left[\mathrm{OH}_{\text {trip }}^{-}\right]>\left[\mathrm{A}_{\text {tot, }, 0}\right]
$$

exists for the premature precipitation of amino acid crystals upon dissolution of the monosodium salts of amino acids. For NaGlu $\cdot \mathrm{H}_{2} \mathrm{O}\left[\mathrm{OH}_{\text {trip }}^{-}\right]=6.5 \times 10^{-9} \mathrm{M}$ and $\left[\mathrm{Glu}_{\text {tot }, 0}\right]=0.0558 \mathrm{M}$, so no formation of glutamic acid crystals is expected upon dissolving sodium glutamine monohydrate crystals in water. This agrees with our observations.

\section{Triple point measurements}

To validate the calculations based on molarities rather than activities and the approximated solubilities of the amino acid 
hydrochloride compounds, the concentrations of the amino acid, chlorine and $\mathrm{pH}$ values at the triple points are measured for the glutamic acid-HCl, glutamic acid- $\mathrm{NaOH}$ and aspartic acid-HCl systems.

The triple point solutions are prepared by adding an excess of amino acid and amino acid hydrochloride crystals to water until the solution is saturated by both compounds and further addition only leads to their precipitation. To reach the triple point equilibrium the solution/crystal mixtures are stirred overnight at $20^{\circ} \mathrm{C}$. After filtration of the slurries the concentrations of amino acid and $\mathrm{Cl}^{-}$as well as the $\mathrm{pH}$ value are determined by the methods described in the experimental section. A similar procedure is used for the glutamic acid/ $\mathrm{NaOH}$ system. The total amino acid concentrations are determined in three different ways: i) by HPLC; ii) evaporation of a known volume of solution and weighting the carefully dried residue, followed by correction for $\mathrm{Cl}^{-}$; iii) Estimation on the basis of the $\mathrm{pH}$ value and using the measured $\mathrm{Cl}^{-}$concentration. The last approach uses the dependence of the total amount of amino acid on $\mathrm{pH},\left[\mathrm{Cl}^{-}\right]$and the solubility of the neutral compound $\left[\mathrm{A}_{\mathrm{slb}}\right]$ :

$$
\left[\mathrm{A}_{\text {tot }}\right] \cong\left[\mathrm{A}^{+}\right]+\left[\mathrm{A}_{\text {slb }}\right]=\left[\mathrm{Cl}^{-}\right]-\left[\mathrm{H}_{3} \mathrm{O}^{+}\right]+\left[\mathrm{A}_{\text {slb }}\right]
$$

A similar relation holds for the glutamic acid/NaOH system

$$
\left[\mathrm{A}_{\text {tot }}\right] \cong\left[\mathrm{A}^{-}\right]+\left[\mathrm{A}_{\mathrm{slb}}\right] \cong\left[\mathrm{Na}^{+}\right]-\left[\mathrm{OH}^{-}\right]+\left[\mathrm{A}_{\mathrm{slb}}\right]
$$

The results of the measurements for the three systems are summarized in Table 3.

It should be mentioned that the evaporation method gives rise to enhanced $\mathrm{HCl}$ evaporation with respect to $\mathrm{H}_{2} \mathrm{O}$ at the latest moments, when $[\mathrm{HCl}]$ exceeds the concentration of 9 molal in the solution. ${ }^{17,18}$ However, as the $\left[\mathrm{A}_{\text {evap }}\right]$ values in table 3 are in the same range of magnitude as the $\left[A_{\text {tot }}\right]$ values determined by other methods, this effect does not play an important role.

The locations of the measured triple points of the different amino acid systems are indicated in the calculated phase diagrams of Fig. 6 and 7. As expected, these positions differ somewhat from the calculated triple point concentration values, but the conclusions drawn remain valid. As can be recognized for both the Glu-Cl systems and the Asp-Cl systems, the total amount of amino acid, [ $\left.\mathrm{A}_{\text {average}}\right]$, is again less than the chlorine concentration $\left[\mathrm{Cl}^{-}\right]$in both cases. This implies that upon dissolving GluCl or AspCl crystals in water one enters the $\mathrm{L}-\mathrm{Glu}_{\mathrm{S}}$ or $\mathrm{L}-\mathrm{Asp}_{\mathrm{s}}$ regime in the phase diagram, leading to the concomitant crystallization of the neutral amino acid species, as observed. This conclusion also follows from the fact that $\left[\mathrm{H}_{3} \mathrm{O}^{+}\right]>\left[\mathrm{A}_{\text {tot, } 0}\right]$ at the triple point of both systems, i.e. $0.50 \mathrm{M}>0.0558 \mathrm{M}$ for GluCl and $0.78 \mathrm{M}>$ $0.0316 \mathrm{M}$ for AspCl.

For the Glu-Na system $\left[\mathrm{A}_{\text {average }}\right]>\left[\mathrm{Na}^{+}\right]$. As a consequence, the NaGlu dissolution line will not enter the $\mathrm{L}_{-} \mathrm{Glu}_{\mathrm{s}}$ domain and, as observed, no concomitant crystallization will occur upon dissolving NaGlu crystals. This conclusion also follows from the fact that $\left[\mathrm{OH}^{-}\right]<\left[\mathrm{Glu}_{\mathrm{slb}}\right]$, i.e. $1.8 \times 10^{-8} \mathrm{M}<0.0558 \mathrm{M}$.

We also determined the $\mathrm{L}-\mathrm{L}+\mathrm{GluCl}_{\mathrm{s}}$ boundary line by measuring the solubility of GluCl crystals in aqueous solutions with different $\mathrm{HCl}$ concentrations. This was realized by weighting the solid after solvent evaporation and careful drying in a desiccator. The results are given in the experimental phase diagram of the Glu-HCl system in shown Fig. 8. In this diagram the $\mathrm{L}-\mathrm{L}+\mathrm{Glu}_{\mathrm{s}}$ boundary is drawn as a straight line starting from the solubility value of the amino acid at zero $\mathrm{HCl}$ concentration to the triple point coordinates as given in Table 3 .

As mentioned before, the solvent evaporation method can introduce some errors in the measured L - L + GluCls boundary line points. However, we expect that these errors are not dramatic as pointed out for $\left[\mathrm{A}_{\text {evap }}\right]$ during the triple point measurements of $\left[\mathrm{A}_{\text {tot }}\right]$.

\section{Avoidance and occurrence of concomitant crystallization}

To grow GluCl (AspCl) crystals without co-precipitation of the neutral amino acid one has to operate in the $\mathrm{L}+\mathrm{GluCl}_{\mathrm{S}}$ $\left(\mathrm{L}+\mathrm{AspCl}_{\mathrm{S}}\right)$ domains of the phase diagrams. This can easily be realized by adding some $\mathrm{HCl}$ to the solution. In this way the driving force for crystallization, $\Delta \mu$, can be controlled as well. Namely, by using the relation

$$
\Delta \mu=R T \ln \left[\frac{\left[\mathrm{A}^{+}\right]\left[\mathrm{Cl}^{-}\right]}{K_{\mathrm{ACl}}}\right]
$$

with $\left[\mathrm{A}^{+}\right] \cong\left[\mathrm{A}_{\text {tot }}\right]$ and $\left[\mathrm{Cl}^{-}\right]$the actual amino acid and chlorine concentrations in the solution. $K_{\mathrm{ACl}}$ can be derived from the amino acid and chlorine concentrations measured at the triple point.

In our study we used acidic amino acids, ${ }^{20}$ however we expect concomitant crystallisation also to occur for the

Table 3 Measured concentration values in mol per liter solution at the triple points of the Glu- $\mathrm{HCl}, \mathrm{Glu}-\mathrm{NaOH}$ and $\mathrm{Asp}-\mathrm{HCl}$ systems ${ }^{a}$

\begin{tabular}{llllllll}
\hline System & {$\left[\mathrm{A}_{\mathrm{HPLC}}\right]$} & {$\left[\mathrm{A}_{\text {evap }}\right]$} & {$\left[\mathrm{A}_{\mathrm{pH}}\right]$} & {$\left[\mathrm{A}_{\text {average }}\right]$} & {$\left[\mathrm{Cl}^{-}\right]$} & {$\left[\mathrm{Na}^{+}\right]$} & {$\left[\mathrm{H}^{+}\right]$or $\left[\mathrm{OH}^{-}\right](\mathrm{from} \mathrm{pH})$} \\
\hline Glu-HCl & $1.66 \pm 0.02$ & $1.60 \pm 0.02$ & $1.72 \pm 0.03$ & 1.66 & $2.17 \pm 0.02$ & $* *$ & $0.50 \pm 0.01$ \\
& $6 \times 2$ & $4 \times 2$ & $3 \times 2$ & & $4 \times 2$ & $2 \times 2$ \\
Glu-NaOH & $2.46 \pm 0.02$ & $* *$ & $2.33 \pm 0.01$ & 2.40 & $* *$ & $2.28 \pm 0.01$ & $(1.78 \pm 0.04) \cdot 10^{-8}$ \\
& $2 \times 1$ & $* *$ & $2 \times 1$ & & $2 \times 1$ & $2 \times 1$ \\
Asp-HCl & $1.45 \pm 0.04$ & $1.38 \pm 0.08$ & $1.15 \pm 0.09$ & 1.33 & $1.90 \pm 0.07$ & $* *$ & $0.78 \pm 0.06$ \\
& $3 \times 2$ & $3 \times 2$ & $3 \times 1$ & & $3 \times 3$ & $3 \times 1$
\end{tabular}

${ }^{a}$ The indications $i \times j$ given for each concentration value indicate $i$ independent experiments with each $j$ measurements. 


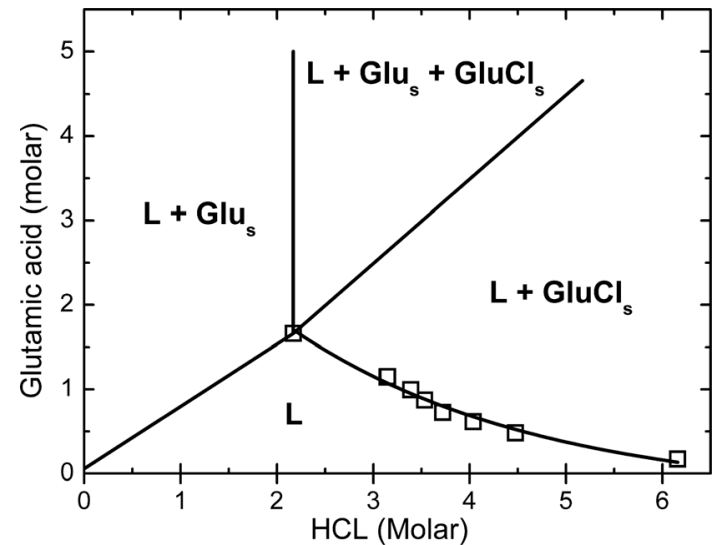

Fig. 8 Experimental phase diagram of the glutamic acid hydrochloride system.

dissolution of the sodium salts of basic amino acids. ${ }^{20}$ Preliminary phase diagram calculations using typical $K a_{1}, K a_{2}$ and amino acid solubility values suggest that concomitant dissolution may also occur upon dissolution of "neutral" amino acid chloride crystals. Here the slope of the calculated $\mathrm{L}-\mathrm{L}+\mathrm{A}_{\mathrm{s}}$ boundary line is less than one. However, as the crystallography and the solubility of these halide salts are not considered (known), the locations of the triple points cannot be estimated and no definite conclusions can be drawn for the individual cases.

This work unavoidably concerns the formal definitions of polymorphs, salts and co-crystals as elaborated in ref. 25. The single component amino acid crystals can be polymorphic, such as $\alpha$ and $\beta$ glutamic acid. Upon reaction with $\mathrm{HCl}$ and $\mathrm{NaOH}$ they form salts with ionic characteristics. Sodium glutamate monohydrate is a hydrated salt. The pairs di-leucine hydrochloride and leucine chloride monohydrate can be considered as different compounds. Leucine hydrochloride monohydrate is a hydrated salt, whereas Leu-Leu ${ }^{+}$ (i.e. di-leucine) hydrochloride can be considered as a salt co-crystal. No other co-crystals following the definition of ref. 25 were encountered in this study.

\section{Conclusions}

Dissolving glutamic acid, aspartic acid or leucine hydrochloride salt crystals in water, leads to concomitant crystallization of the neutral amino acid species. No simultaneous crystallization of glutamic acid is observed upon dissolving monosodium glutamate monohydrate crystals. These observations are explained on the basis of calculated phase diagrams of the $\mathrm{Glu} / \mathrm{HCl}, \mathrm{Asp} / \mathrm{HCl}, \mathrm{Leu} / \mathrm{HCl}$ and $\mathrm{Glu} / \mathrm{NaOH}$ systems. By dissolving the hydrochloride salt crystals in water one unavoidably enters the liquid + solid amino acid region of the phase diagram, which leads to the precipitation of the neutral amino acid. The boundary between the liquid and the liquid + solid amino acid regions is not traversed upon dissolving the sodium salt of glutamic acid. Triple point measurements using several analytical methods confirm the conclusions based on the calculated phase diagrams.

\section{References}

1 M. Delfino, J. P. Dougherty, W. K. Zwicker and M. M. Choy, J. Cryst. Growth, 1976, 36, 267-272.

2 K. Selvaraju, R. Valluvan and S. Kumararaman, Mater. Lett., 2006, 60, 1565-1569.

3 M. Narayan Bath and S. M. Dharmaprakash, J. Cryst. Growth, 2002, 236, 376-380.

4 L. Pasteur, C. R. Hebd. Séanc. Acad. Sci. Paris, 1848, 26, 535.

5 R. Yoshioka, in Topics of Current Chemistry, ed. K. Sakai, N. Hirayama and R. Tamura, Springer-Verlag, Berlin, 2007, vol. 269, pp. 83-132.

6 E. Havinga, Chem. Weekbl., 1941, 38, 642-644; E. Havinga, Biochim. Biophys. Acta, 1954, 13, 171-174; D. K. Kondepudi, R. J. Kaufman and N. Singh, Science, 1990, 250, 975-977.

7 C. Viedma, Phys. Rev. Lett., 2005, 94, 065504.

8 W. L. Noorduin, T. Izumi, A. Millemaggi, M. Leeman, H. Meekes, W. J. P. van Enckevort, R. M. Kellog, B. Kaptein, E. Vlieg and D. G. Blackmond, J. Am. Chem. Soc., 2008, 130, 1158.

9 L. Spix, A. Alfring, H. Meekes, W. J. P. van Enckevort and E. Vlieg, Cryst. Growth Des., 2014, 14, 1744-1748.

10 W. L. Noorduin, B. Kaptein, H. L. M. Meekes, W. J. P. van Enckevort, R. M. Kellogg and E. Vlieg, Angew. Chem., Int. Ed., 2009, 48, 4581-4583.

11 C. Sano, Am. J. Clin. Nutr., 2009, 90, 728S-732S.

12 T. Kawakita, L-Monosodium Glutamate, in Kirk-Ohner Encyclopedia of Chemical Technology, John Wiley and Sohns, Inc, 1992, vol. 2, pp. 571-579.

13 L. Golič and W. C. Hamilton, Acta Crystallogr., Sect. B: Struct. Crystallogr. Cryst. Chem., 1972, 28, 1265-1271.

14 L. J. Atwood, S. J. Dalgarno, M. J. Hardi and C. L. Raston, Chem. Commun., 2005, 337-339.

15 D. Korkmaz, pdf file available online at http://academic. brooklyn.cuny.edu/esl/gonsalves/tutorials/Writing_a_Lab_Report/ xPrecipitation\%20Titration\%20edited\%203.pdf.

16 G. M. Sheldrick, Acta Crystallogr., Sect. A: Found. Crystallogr., 2008, 64, 112-122.

17 D. F. Othmer and L. M. Naphtali, Ind. Eng. Chem., 1956, 1, 6-10.

18 J. J. Fritz and C. R. Fuget, Ind. Eng. Chem., 1956, 1, 10-12.

19 B. Harjo, K. Ming Ng and C. Wibowo, Ind. Eng. Chem. Res., 2007, 46, 2814-2822.

20 J. McMurry, Organic Chemistry, Brooks/Cole, Pacific Grove, USA, 5th edn., 1999, pp. 1076-1077.

21 P. Mougin, D. Wilkinson and K. J. Roberts, Cryst. Growth Des., 2002, 2, 227-234.

22 M. Kitamura, Journal of Crystal Growth, 1989, 96, 541-546.

23 A. Apelblat and E. Manzurola, J. Chem. Thermodyn., 1997, 29, 1527-1533.

24 H. Matsuo, Y. Suzuki and S. Sawamura, Fluid Phase Equilib., 2002, 200, 227-237.

25 S. Aitipamula, et al., Cryst. Growth Des., 2012, 12, 2147-2152. 